\title{
El virus respiratorio sincicial: patógeno de niños... y de grandes
}

\author{
PATRICIA V. DÍAZ A.* y LUIS FIDEL AVENDAÑO C.*
}

\section{Respiratory Syncytial Virus: a pathogen for the small ones and the big ones}

Since respiratory syncytial virus (RSV) was identified in 1956, its impact as the main cause of severe acute lower respiratory infections in infants has been shown. Studies about RSV immunopathogenesis have demonstrated that the host immune response is important in protecting from re-infections. The presence of RSV in exacerbation of chronic diseases as COPD and bronchial asthma in adults and its severity in cases with immunodeficiency has been also related to an inadequate response. The actual knowledge on the molecular structure and functions of the virus has allowed to improve diagnosis and to develop new strategies for vaccines and antiviral drugs. The etiologic diagnosis in children is easier than in adults due to the higher viral shedding; therefore techniques based on antibody reactions (immunofluorescence, immunocromatography, etc) are good enough in this group. By contrast, in adults, highly sensitive molecular techniques are needed. Although the advances in understanding the pathogenesis process in neonates and infants, many pathogenic factors still need to be elucidated. The virus strains, viral loads and immune response have been described as important players; however, the changes on the host immunity to RSV according to age and co-morbidities associated to severity of illness needs to be explored. RSV has been known as a children pathogen, nowadays this agent is being recognized as an important agent in adults, especially in those with chronic diseases, immunodeficiency and in immune-senescence.

Key words: Respiratory syncytial virus; Infant; Adult; Respiratory tract infections; Viruses.

\section{Resumen}

Desde el descubrimiento del virus respiratorio sincicial (VRS) en 1956, se ha demostrado en todo el mundo su impacto como el principal causante de infecciones respiratorias agudas bajas (IRAB) que requieren hospitalización en el lactante. Posteriormente se ha descrito que una inadecuada respuesta inmune favorece reinfecciones en la infancia. Más recientemente, numerosos trabajos epidemiológicos lo han asociado a IRAB en adultos, especialmente de tercera edad y en ciertos pacientes inmunocomprometidos. Se ha avanzado en el conocimiento de la estructura y función de los diferentes componentes del VRS, lo que ha permitido facilitar su diagnóstico y avanzar en estrategias de desarrollo de antivirales y vacunas. En efecto, el diagnóstico de laboratorio de VRS es muy simple en niños, por su alta excreción viral, pero para demostrar su participación en adultos se requieren técnicas de alta sensibilidad. La patogenia de la infección es muy compleja y muchos aspectos todavía no se han aclarado. Intervienen factores dependientes del virus -cepa, dosis infectiva, capacidad del virus de inhibir la respuesta inmune- $y$ del hospedero humano, como edad, enfermedades concomitantes, integridad del aparato inmune y otros. Se menciona que otros factores como frí, humedad ambiental, contaminación aérea, hacinamiento, también actuarían en combinación con los inicialmente mencionados. Es necesario conocer los mecanismos responsables de la adquisición de inmunidad contra el VRS para entender las estrategias usadas en el intento de desarrollar vacunas, cuyos esfuerzos son todavía infructuosos. Actualmente se conoce bastante del VRS como patógeno de niños. Sin embargo, cada día se documenta más su participación en enfermedades de adultos, por lo que haremos un resumen para promover su consideración como posible patógeno respiratorio.

Palabras clave: Virus respiratorio sincicial; Niño; adulto; Infecciones del tracto respiratorio; Virus.

* Instituto de Ciencias Biomédicas, Facultad de Medicina. Universidad de Chile. 


\section{Epidemiología}

El virus respiratorio sincicial contagia a cerca del $50 \%$ de los niños en su primer año de vida y a los 2 años prácticamente todos han tenido contacto con el virus. Se estima que $2-3 \%$ de las primeras infecciones requiere atención hospitalaria por su gravedad. Por eso, se le considera el principal agente causante de hospitalizaciones infantiles por infección respiratoria aguda baja (IRAB) y el responsable del aumento de la demanda de atención de salud que ocurre todos los inviernos en Chile ${ }^{1,2}$.

En adultos la demostración de la infección por VRS ha estado muy ligada al desarrollo de diagnóstico de laboratorio específico y limitada por la menor excreción de virus en secreciones respiratorias, comparado con los lactantes y niños pequeños. En la década de los '80 se empezó a demostrar la etiología de la infección respiratoria baja por VRS en adultos, comparándola con influenza, basado en técnicas serológicas, aislamiento viral e inmunofluorescencia ${ }^{3-6}$. Posteriormente, el desarrollo del diagnóstico molecular ha permitido demostrar la participación del VRS en muchos cuadros respiratorios del adulto institucionalizado $^{7-12}$, en inmunocomprometidos ${ }^{13} \mathrm{y}$ en adultos con factores de riesgo, en los cuales la infección ha demostrado ser de mayor gravedad. Hoy día se debe considerar la participación viral en entidades clínicas clásicamente relacionadas con bacterias, como la neumonía adquirida en la comunidad, la EPOC y otras ${ }^{14-17}$.

\section{Estructura y replicación del VRS}

El VRS pertenece a la familia Paramyxoviridae, subfamilia Pneumovirinae, género Pneumovirus, teniendo como único hospedero al hombre. En la Tabla 1 se muestra la clasificación y su relación con otros virus de la misma familia que comprometen a seres humanos y a otros mamíferos y aves. Es un virus de $\sim 150 \mathrm{~nm}$ de diámetro, de simetría helicoidal constituido por genoma de una hebra de ARN de polaridad negativa, en cuyas $\sim 15.000$ bases contiene 10 genes que codifican 11 proteínas, 9 estructurales y 2 funcionales. La proteína $\mathrm{N}$ conforma la nucleocápsula que rodea al ARN, donde se adosan las proteínas $\mathrm{L}$ y $P$ (polimerasa). En su envoltura o manto viral lipídico, no proteico, se insertan las glicoproteínas $\mathrm{F}, \mathrm{G}$ y la proteína pequeña hidrofóbica o $\mathrm{SH}$. La proteína $\mathrm{M}$ o de matriz se ubica en la cara interna del manto. Además, hay dos proteínas no estructurales (NS1 y NS2) que participan en la regulación de la replicación, especialmente a inicios tempranos de esta y con influencia en la respuesta inmune del huésped ya que NS2 puede inhibir la respuesta antiviral de Interferones tipo $\mathrm{I}^{18,19}$ (Figura 1).

En base a la reactividad serológica se han determinado dos grupos denominados $\mathrm{A}$ y $\mathrm{B}$, con reactividad cruzada parcial. Las glicoproteínas de superficie $F$ y $G$ tienen importancia en la inmunidad, siendo la $\mathrm{F}$ conservada y la $\mathrm{G}$ variable. El análisis genómico ha permitido clasificar los VRS en genotipos y fenotipos, que muestran la diversidad natural esperable en virus $\mathrm{ARN}^{20,21}$; $\sin$ embargo, aún no se ha logrado relacionar alguna cepa con virulencia o mayor transmisibilidad que explique la amplia forma de presentación clínica y epidemiológica de la infección por VRS. Los análisis de epidemiología molecular o vigilancias se basan en la glicoproteína $\mathrm{G}$ (estudios de genotipos circulantes y sus variaciones en el tiempo), aunque actualmente también están utilizando la glicoproteína F. Los estudios sobre diversidad de patología (o patogenia), no sólo se basan en $\mathrm{G}$, sino que están tomando importancia las proteínas NS, F y L, entre otras ${ }^{22}$.

La fuente de contagio en niños es habitualmente otro niño, el virus se adquiere en la vía aérea mediante contacto directo con secreciones respiratorias eliminadas en forma de aerosoles o depositadas en el ambiente, especialmente en manos y fomites. La puerta de entrada es el tracto respiratorio alto, donde el virus se adsorbe y multiplica en las células epiteliales y difunde por vecindad en el árbol respiratorio. La proteína $\mathrm{G}$ posee un sitio CX3CL1 (fractalquina) en su estructura conservada. Fractalquina es un pequeño péptido con actividad quimiotáctica, por lo que se une a receptores del tipo CX3CR1, lo que puede facilitar la quimiotaxis con otras células que tengan a este receptor ${ }^{23}$. La proteína $\mathrm{F}$ se une

Tabla 1. Clasificación de la familia Paramyxoviridae en subfamilias y géneros

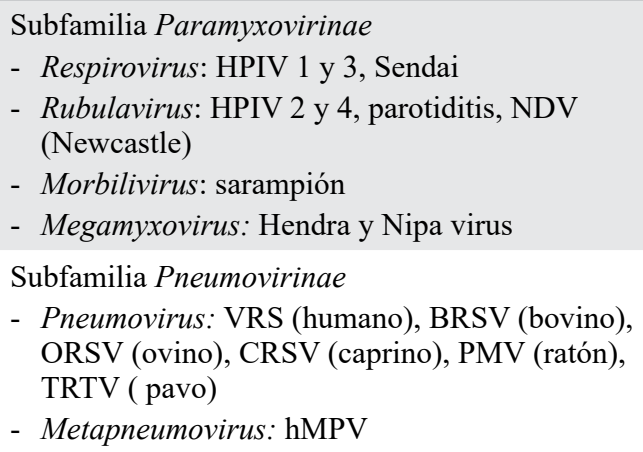


a algunos receptores tipo toll (TLR4) estimulando su expresión en las células epiteliales respiratorias, los que también pueden activarse con diversas sustancias como lipopolisacáridos (LPS) y ácido lipoteitoico (LTA) contenidos en la pared bacteriana $^{24}$. Recientemente se identificó otro receptor para la entrada y replicación del VRS in $v_{i t r o}{ }^{25}$, que involucra a la proteína de fusión $(\mathrm{F})$ fusionándose con la nucleolina en la zona apical de la célula hospedera.

\section{Cuadro clínico y factores de riesgo de gravedad}

El VRS infecta en los primeros años de vida desencadenando una respuesta inmune deficiente. Al no establecerse una memoria inmunológica adecuada, el virus es capaz de re-infectar durante la vida. La gravedad de la infección varía entre leves síntomas respiratorios altos a infección respiratoria aguda baja (IRAB) grave demostrada por una hipoxemia con saturación de oxígeno bajo $95 \%$, obstrucción de la vía aérea, aumento de producción de mucus y compromiso del parénquima pulmonar produciendo una bronquiolitis con o sin bronconeumonía. Se ha descrito factores de riesgo de gravedad como prematuridad, bajo peso de nacimiento, nivel socio-económico bajo, displasia broncopulmonar, cardiopatías congénitas con alteración hemodinámica, edad entre 6 y 12 semanas de vida, inmunodeficiencias por infección por virus de la inmunodeficiencia humana (VIH) y en pacientes trasplantados. Hay factores maternos que han sido relacionados con el aumento de probabilidad de desarrollo de bronquiolitis por VRS, como tabaquismo pre y post natal y bajos niveles de anticuerpos específicos ${ }^{26,27}$.

En lactantes sanos, la primo-infección por VRS es habitualmente leve a moderada ${ }^{28}$. Sin embargo, un 2-3\% de los lactantes presentan bronquiolitis grave que requiere hospitalización ${ }^{1,2}$ e incluso ingreso a unidades de cuidado intensivo. Dado que la mayoría de los casos graves no tienen los factores de riesgo descritos, es muy probable que participen otros factores aún no identificados ${ }^{29}$.

En adultos la infección por VRS puede ser subclínica y afectar el aparato respiratorio alto o bajo con distinta intensidad; en Chile es más frecuente durante las estaciones frías, afectando a la tercera edad. En adultos sanos suele producir rinitis y tos que progresan en 3 a 4 días hacia tos productiva con presencia de sibilancias y crépitos; en casos de pacientes con enfermedades respiratorias crónicas se pueden desencadenar reactivaciones de EPOC y exacerbaciones de asma $^{5-18}$. En estudios experimentales de infección por VRS humano en adultos voluntarios sanos se observó que la sintomatolgía clínica desaparecía pero la inflamación de la vía aérea persistía hasta 28 días post inoculación viral ${ }^{30}$. Las infecciones respiratorias agudas bajas pueden ser de etiología viral o bacteriana y la signo-sintomatología no permite definir un agente etiológico específico. Habitualmente hay fiebre de distinta magnitud, tos y compromiso variable del estado general, lo que parece depender más de factores propios del huésped que del agente involucrado. En efecto, factores como edad, patología concomitante, compromiso al inicio de la enfermedad resultan ser muy determinantes del pronóstico del cuadro $^{31,32}$. Es cada vez más frecuente diagnosticar infección grave por VRS aproximándose en el mayor de 65 años a la mortalidad por influenza ${ }^{33}$, lo que se ha relacionado con la alteración de la inmunidad en el adulto mayor ${ }^{34}$. Los distintos sistemas de evaluación de la gravedad de neumonía consideran una serie de características del paciente al inicio de la enfermedad, pero no la etiología específica

\section{Patogenia del VRS}

Los procesos patogénicos de gravedad no están bien determinados. En cuanto a factores virales, se ha descrito la carga viral como importante en el desarrollo de enfermedad, sin embargo, los hallazgos continúan siendo controversiales ${ }^{35,36}$. Estudios recientes han detectado una replicación viral prolongada y rebote de la carga viral hasta el mes de infección, especialmente en menores de 70 días de $v i d a^{37}$. En relación a la respuesta inmune, existen diversos estudios que la describen como un factor fundamental, con un aumento de citoquinas pro-inflamatorias y una disminución de la respuesta inmune innata celular ${ }^{38-41}$.

\section{Respuesta inmune innata al VRS}

El VRS penetra habitualmente a la vía aérea por la nariz, donde es reconocido por los receptores TLR4 y CX3CR 1 presentes en las células epiteliales, las que sufren cambios fusionándose y activándose. La fase inicial en el citosol, con activación o translocación al núcleo de factores de transcripción, llevan a cambios en la expresión génica y la adquisición de nuevas funciones entre ellas la producción de citoquinas como IFN 


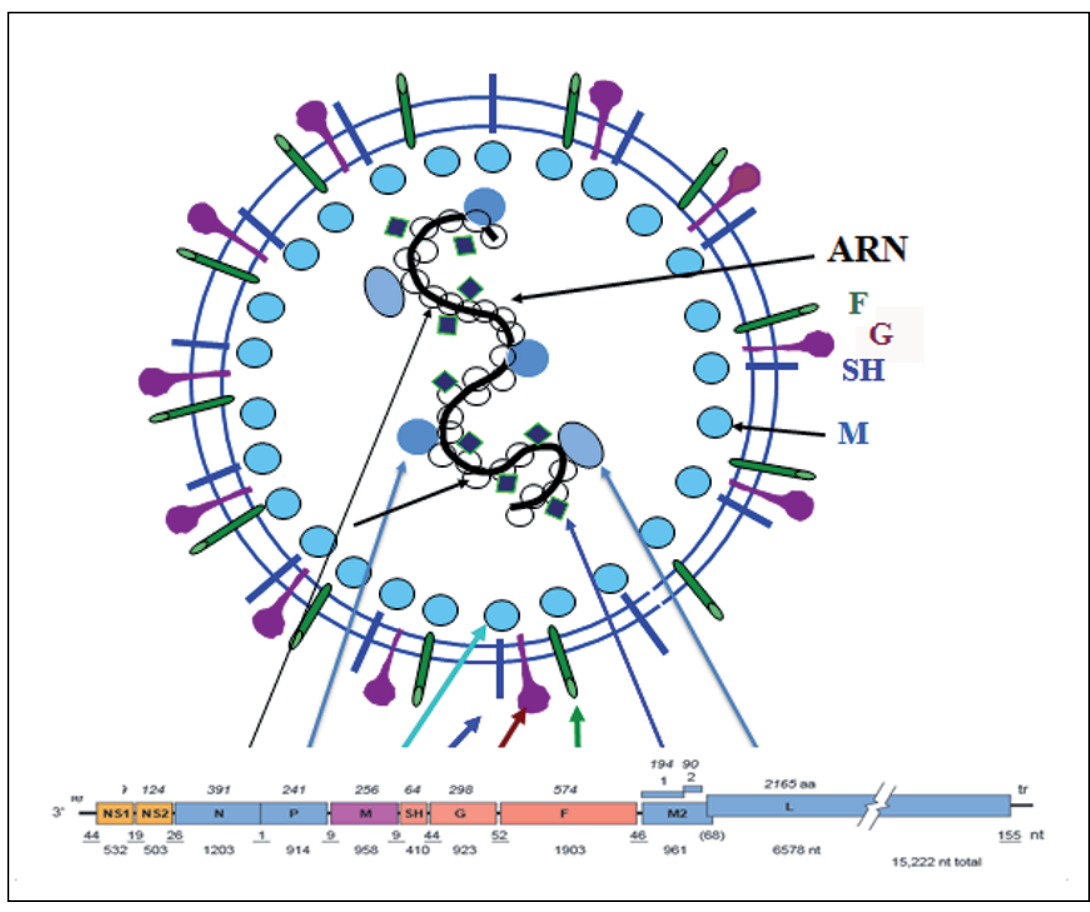

Figura 1. Esquema de la estructura del VRS, que muestra la disposición de sus componentes y su relación con los genes que los codifican. ARN: ácido Ribonucleico; F, G,M y $\mathrm{SH}$ : proteínas del virus. tipol $(\alpha / \beta)$, mediante los factores de transcripción STAT 1, STAT2 e IRF9, mientras la activación de los factores de transcripción NFkB estimulan la producción de interleuquinas pro-inflamatorias (TNF- $\alpha$, IL-6,IL-8,IL-1 $\beta$ ). Esta respuesta de inmunidad innata dura alrededor de 3 días. La inflamación como parte de la respuesta inmune innata atrae neutrófilos a la vía aérea y es importante como mecanismo para eliminar el agente extraño; sin embargo, si es muy exagerada produce daño ${ }^{38,42}$. Las células dendríticas presentes en la vía aérea transportan los diversos antígenos del VRS a sitios activos como el sistema linfocitico asociado a mucosas (BALT) donde se estimula la respuesta efectora adaptativa que es específica, la que es orquestada por este primer contacto del virus con el sistema inmune ${ }^{43}$ (Figura 2).

Los receptores celulares presentes en las células epiteliales, dendríticas, macrófagos, y otras que reconocen patrones moleculares (PRRs) importantes en la adsorción y en respuesta al VRS son: TLR4, TLR3, TLR2/6, TLR7/8. Los interferones I (IFN $\alpha$ y $\beta$ ) que actúan en los receptores de IFN (IFNAR) presentes en todas las células, les confiere un estado antiviral que inhibe la replicación del virus y estimula la apoptosis de la célula infectada ${ }^{44}$. Por el contrario, el VRS tiene 2 proteínas NS1 y NS2 que tienen la propiedad de inhibir las vías de señalización de producción de los IFN y de esta manera favorecer la replicación viral $^{20}$. Otra fuente de IFNs son las células NK, las que están disminuidas en el pulmón y en la sangre periférica de pacientes con VRS grave ${ }^{41}$.

El TLR4 fue el primer PRR involucrado en la respuesta al VRS demostrando que la proteína F del VRS al unirse al receptor TLR4/CD14 de la membrana plasmática en mononucleares de sangre periférica, induce la producción de IL$6^{24}$. En ratas que no presentan este TLR (ratas knock-out), la eliminación del virus está alterada, sugiriendo un rol protector. En lactantes se ha descrito un polimorfismo de TLR4 asociado a bronquiolitis grave. A la luz de estos estudios se puede inferir que una de las causas de gravedad en bronquiolitis podría ser la disminución de función de TLR4 mostrada en monocitos obtenidos de sangre de cordón umbilical comparado con monocitos obtenidos de sangre de adultos ${ }^{45}$.

Hay estudios que han demostrado una relación entre los niveles de algunas interleuquinas proinflamatorias (IL-6, IL-8 e IL1- $\beta$ ) y la gravedad de la infección considerando los días de requerimiento de oxígeno durante la hospitalización ${ }^{39}$. El aumento de interleuquinas con características de quemoquina en la vía aérea como la IL-8 (CXCL8) atrae células especialmente neutrófilos, produciendo necrosis y luego fagocitosis de las células infectadas ${ }^{42}$.

En la bronquiolitis los neutrófilos están presentes en la vía aérea alta y baja. Tienen como fun- 


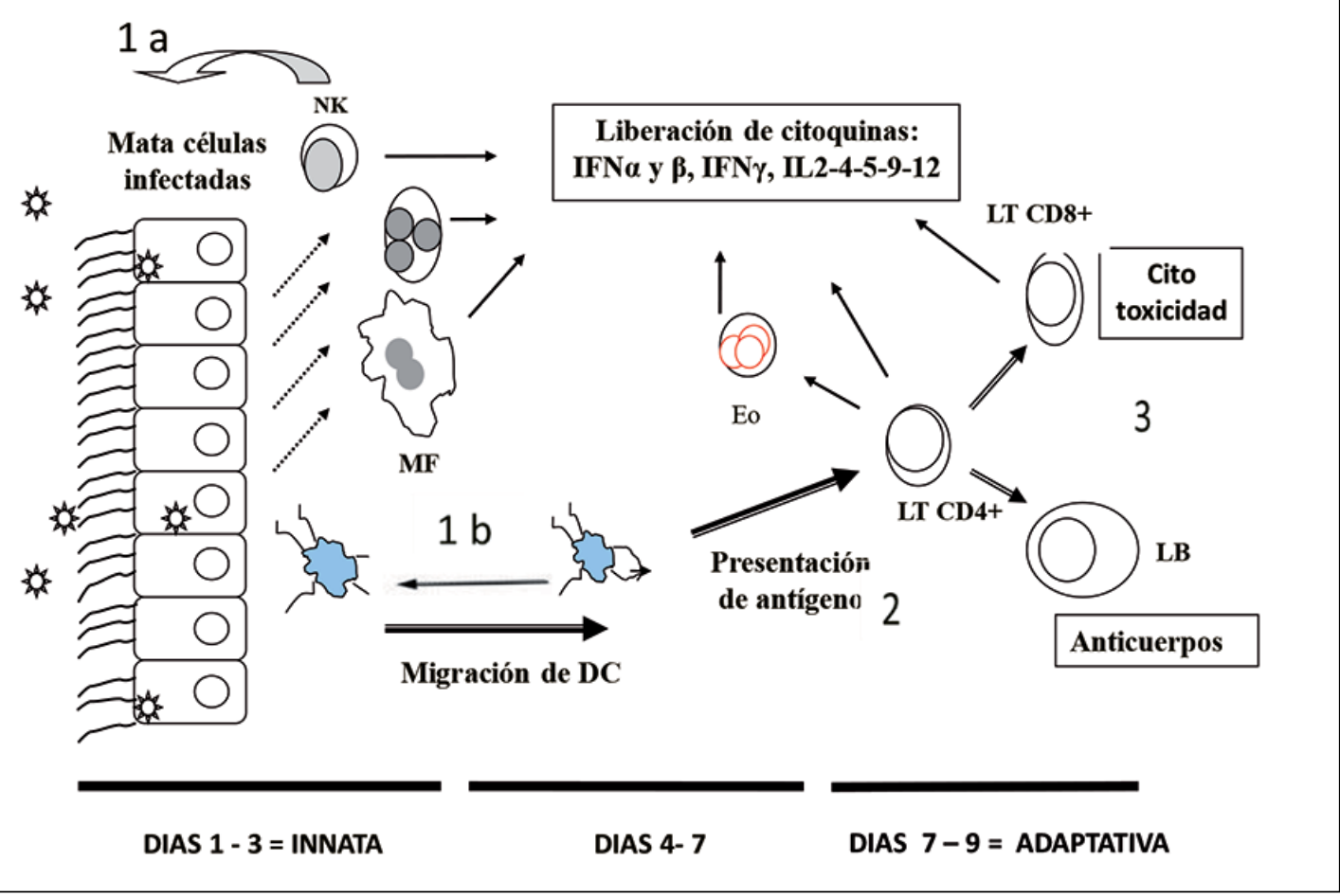

Figura 2. Respuesta inmune a infección por VRS. Las proteínas F y G del VRS interactúan con los receptores TLR-4 y CX3CR1 respectivamente, de las células de la mucosa epitelial . Esto desencadena (1a) la respuesta innata en las células ciliares, macrófagos y células dendríticas de la mucosa en los primeros de 3 días, a través de la producción de IFN tipo I $\alpha / \beta$ y de la activación de factores que estimulan la producción de citoquinas pro-inflamatorias (TNF- $\alpha$, IL-6, IL-8,IL$1 \beta)$; y a su vez, (1b) las células dendríticas presentes en la vía aérea transportan diversos antígenos del VRS a sitios activos del sistema linfático asociado a mucosas (BALT) donde se refuerza la respuesta innata con más migraciones de células a la mucosa; (2) por este primer contacto del virus con el sistema inmune se orquesta la respuesta efectora adaptativa específica de LT CD4, LT CD8 y LB desde el día siete. Esta respuesta adquirida, contribuye a la eliminación de la infección, especialmente por acción de LT CD8 e IFN $\gamma$ dejando respuesta mediada por anticuerpos (3) y células $\mathrm{T}$ sensibilizadas que protegerán contra futuras reinfecciones.

ción eliminar las células infectadas, pero además poseen enzimas que al liberarlas destruyen tejido. Se ha descrito que pacientes con polimorfismo genético de la región promotora de IL-8 producen mayor cantidad de esta quemoquina, presentan bronquiolitis más graves. Además, los neutrófilos presentan receptores esteroidales tipo $\beta$ que -a diferencia de los receptores esteroidales tipo $\alpha$ - no tienen respuesta anti-inflamatoria, lo que explica en parte que el tratamiento con corticoides es inefectivo en pacientes con bronquiolitis ${ }^{46}$.

\section{Relación de la respuesta inmune innata con la respuesta inmune tardía o adaptativa}

La inmunidad innata participa en la activación de la respuesta específica de linfocitos $\mathrm{T}$ y $\mathrm{B}$ frente al virus. La activación linfocitaria requiere de dos señales, la presentación del antígeno por células presentadoras de antígeno (CPA) y de moléculas co-estimuladoras producidas durante la respuesta innata. Entre las CPA, las células dendríticas plamacitoides (pDC) son importantes productores de IFN $\alpha / \beta$ y junto a células dendríticas mieloides (DC) se movilizan hacia la mucosa respiratoria durante la infección por $\mathrm{VRS}^{43}$. En los neonatos y durante la inmunosenescencia se ha demostrado inmadurez de pDC con baja presencia e inhabilidad de producir IFNs y de procesar el virus ${ }^{34}$. Además, la capacidad de las proteínas NS del VRS de inhibir la maduración de las DC hace que en el neonato el VRS obstaculice la presentación por las CPA y el "priming" a las células $\mathrm{T}$ específicas; por lo tanto no genera una respuesta de memoria adecuada. Esto permite la re-infección incluso con la misma cepa viral y en el mismo periodo epidémico. Se ha reportado una inmunidad parcial post VRS que se manifiesta con re-infecciones ${ }^{47}$. En el adulto la patogenia 
del VRS es aún menos conocida que en el niño. En adultos los anticuerpos neutralizantes tipo IgG contra proteína $\mathrm{F}$ confieren protección contra la infección ${ }^{48}$. Ademas, la participación de linfocitos T CD8+ de memoria específicos contra VRS confiere protección y disminución de la carga viral en adultos ${ }^{3}$.

Palivizumab, un anticuerpo monoclonal humanizado de gran afinidad, es protector y actúa como anticuerpo neutralizante anti proteína $\mathrm{F}$ del VRS. Los anticuerpos de tipo IgG atraviesan la placenta durante el último trimestre del embarazo y confieren protección transitoria al recién nacido y lactante menor siendo los títulos altos de anticuerpos maternos los que se correlacionan con enfermedad más benigna. Pero los anticuerpos duran máximo 6 meses y al tercer mes están en un $50 \%$ de su nivel inicial ${ }^{49}$.

Es conocido que la infección por VRS es más grave en los extremos de la vida, debido a una disminución de los mecanismos inmunológicos de respuesta frente a las infecciones. En el adulto mayor se observa una respuesta inmune innata e inmunidad adaptativa deficitaria en su actividad. En general todas las células que participan en la respuesta inmune están alteradas en su función ${ }^{34,50-51}$ y esta singularidad hace que la respuesta a vacunas sea más ineficiente que en los jóvenes. Por otro lado, en la tercera edad es frecuente la neumonía por VRS, que puede ser muy grave y en especial en pacientes con déficit inmunitario inducido como trasplante de médula y pulmón en quienes la infección por VRS puede ser fatal ${ }^{9,12}$.

En resumen, el mecanismo de daño del VRS se produce en individuos que por su edad o por otra condición, la respuesta inmune está alterada acentuando la acción del virus ${ }^{52,53}$. Sin embargo, a pesar de la extensa investigación desarrollada para lograr un mejor conocimiento sobre el virus y su patogenia (importantes para el desarrollo de vacunas) aún no se ha podido lograr. La o las vacunas $\mathrm{u}$ otro tratamiento a desarrollar deben superar y vencer el déficit inherente de respuesta inmune del individuo.

\section{Diagnóstico}

En el lactante se ha descrito la primoinfección como una infección autolimitada preferentemente en el primer semestre de la vida, caracterizada por escasa fiebre, tos, disnea con retracción costal y presencia de sibilancias; el cuadro llega a su máximo a los 5 a 7 días y empieza a declinar. Demora alrededor de dos semanas en norma- lizarse, pero durante los siguientes seis meses el lactante puede manifestar signos menores de obstrucción bronquial ante otros cuadros virales En los países de clima continental debe sospecharse infección por VRS en las estaciones frías. El diagnóstico de laboratorio permite confirmar fácilmente la sospecha etiológica, gracias a que los niños eliminan gran cantidad de partículas virales en sus secreciones respiratorias. El diagnóstico en adultos es más difícil. En adultos se debe sospechar en aquellos con factores de riesgo (inmunocomprometidos, portadores de insuficiencia cardíaca crónica o EPOC o de tercera edad) que presentan cuadros respiratorios bajos, con signos obstructivos moderados. En estudios de neumonía adquirida en la comunidad en Chile se observó que la radiografía de tórax muestra imágenes bilaterales con compromiso alveolar y el hemograma y la VHS no tienen características distintivas especiales ${ }^{17}$. Los patrones radiológicos y hematológicos no permiten diferenciar infecciones virales o bacterianas. Por eso es necesario el laboratorio para definir la etiología.

Se han implementado numerosas técnicas de inmunodiagnóstico (inmunofluorescencia, ELISA, inmunocromatografía) que tienen alta sensibilidad -incluso mejor que el clásico aislamiento en cultivo celular- son fáciles de montar en laboratorios clínicos y dan resultados en pocas horas. La simple repetición del examen ayuda a solucionar dudas clínicas sobre diagnóstico, evolución inesperada, contagios intrahospitalarios, etc. ${ }^{1,2}$.

Además existen técnicas moleculares basadas en amplificación de ácidos nucleicos, que abarcan PCR, RT PCR, Arrays, LUMINEX y otras, de alta sensibilidad ya implementadas en muchos laboratorios ${ }^{11}$. Su uso se reserva para casos especiales y para adultos, pues éstos eliminan poca cantidad de virus en sus secreciones, por lo que las técnicas de inmunoanálisis suelen tener bajo rendimiento ${ }^{17}$. Actualmente hay varios paquetes de diagnóstico múltiple de buena sensibilidad, que incluso detectan virus y bacterias ${ }^{54-56}$.

\section{Tratamiento}

No existen antivirales específicos de probada utilidad clínica ${ }^{57}$. Sólo la ribavirina se ha ensayado en cuadros muy graves en niños, con resultados discordantes; además, sus efectos secundarios son importantes ${ }^{57}$. los medicamentos -antivirales, broncodilatadores, corticoides- son de discutible utilidad. El tratamiento básico consiste en mantener la vía aérea superior permeable con 
aseo nasal y de secreciones faríngeas; facilitar una buena hidratación y una alimentación que le permitan tolerar los primeros días de enfermedad; monitorear la saturación de oxígeno si hay franca dificultad respiratoria; administrar oxígeno si se requiere. Actualmente hay muchas formas de administrar oxígeno suplementario, desde nariceras hasta ventilación asistida, que han mejorado notablemente el pronóstico de los casos graves en lactantes. En décadas anteriores fallecían en Chile más de 700 casos en cada temporada invernal, lo que se ha reducido, sin contar con terapia específica ${ }^{58}$.

En adultos la carencia de síntomas patognomónicos y de la nítida estacionalidad descrita en niños obliga a utilizar exámenes de laboratorio microbiológico molecular para definir la causa y plantear la mejor terapéutica posible. Esta consiste en una terapia de mantención, oxigenoterapia y en un manejo adecuado de las patologías asociadas, que son las determinantes del pronóstico.

\section{Vacunas}

Dadas la alta contagiosidad del VRS y la mala calidad de la inmunidad que deja la infección natural, las esperanzas para una efectiva prevención están orientadas hacia el desarrollo de una vacuna. La glicoproteína $\mathrm{F}$ ha sido blanco de muchos estudios por ser conservada entre las variantes de VRS y por inducir anticuerpos neutralizantes, los que se han demostrado protectores de la infección. En efecto, el uso de anticuerpos anti F monoclonales humanizados ha demostrado proteger de la infección a individuos de alto riesgo, como son los prematuros ${ }^{59,60}$. Por otro lado, el mejor conocimiento de la biología del virus y avances en biotecnología han permitido la preparación de nuevos candidatos de vacunas tanto inactivadas como atenuadas. En general, el desarrollo de vacuna ha seguido los caminos históricamente realizados con otros virus: una vacuna inactivada o una atenuada. Inicialmente se usaban métodos físico- químicos para obtener la primera y para la segunda selección de mutantes mediante pasaje viral en hospederos no habituales. Actualmente, con el desarrollo de la biología molecular se pueden preparar ambos tipos de candidatos en forma más rápida y eficiente ${ }^{61}$.

La primera vacuna contra VRS se preparó de la manera habitual en la década de los '60, inactivando el virus con formalina; sin embargo, resultó no sólo ineficaz, sino deletérea, porque produjo reacciones graves y algunos fallecimientos en los niños que posteriormente tuvieron contacto natural con el virus ${ }^{62}$. Aún se discuten las causas de esta reacción. Este hecho ha retardado el desarrollo de una vacuna contra VRS, pues obliga primero a demostrar con extrema acuciosidad la inocuidad del candidato antes de seguir su desarrollo.

Existen muchos problemas para el desarrollo de una vacuna, pues la infección se presenta tempranamente en la vida, antes de los 3 meses, edad en que la inmunidad no ha madurado; la presencia de anticuerpos maternos a esa edad podría inhibir la respuesta de anticuerpos a una vacuna atenuada. La situación actual es que hay muchos candidatos de vacunas en distintas fases de desarrollo, pero muy pocos han alcanzado la fase clínica III ${ }^{63,65}$. Incluso algunas estrategias se dirigen a vacunar a la embarazada, para obtener una transferencia de anticuerpos que protejan al niño por lo menos por el primer semestre de vida $^{66}$.

Se estima que no habrá alguna vacuna disponible en el mercado para prevenir la infección por VRS antes de cinco años. Además, debemos tener en perspectiva que la vacuna contra el sarampión -otro virus de la familia Paramyxoviridae - ha demorado cincuenta años en eliminar la infección en algunas regiones del mundo, en circunstancias que el virus deja inmunidad duradera y la vacuna es muy buena y fácil de preparar. Así, cuando aparezca la vacuna contra el VRS demorará varias décadas en lograr controlar la circulación del virus.

\section{Bibliografía}

1.- AVENDAÑO L F, LARRAÑAGA C, PALOMINO M A, GAGGERO A, MONTALDO G, SUÁREZ M, et al. Community and Hospital acquired Respiratory Syncytial Virus Infections in Chile. Ped Infect Dis J 1991; 10: $564-8$

2.- AVENDAÑO L F, PALOMINO M A, LARRAÑAGAC. Surveillance for Respiratory Syncytial virus in infants hospitalized for acute lower respiratory infection in Chile (1989 to 2000). J Clin Microbiol 2003; 41: 4879-82.

3.- FINGER R, ANDERSON L J, DICKER R C, HARRISON B, DOAN R, DOWNING A, et al. Epidemic infections caused by respiratory syncytial virus in institutionalized young adults. J Infect Dis 1987; 155: 1335-9.

4.- FALSEY A R, CUNNINGHAM C K, BARKER W H, KOUIDES R W, YUEN J B, MENEGUS M, et al. Respiratory Syncytial virus and Influenza A infections in the hospitalized elderly. J Infect Dis 1995; 172: 389-94.

5.- DOWELL S F, ANDERSON L J, GARY H E, ERDMAN D, PLOUFFE J F, FILE T M, et al. Respiratory 
syncytial virus is an important cause of communityacquired lower respiratory infection among hospitalized adults. J Infect Dis 1996; 174: 456-62.

6.- THOMPSON W W, SHAY D K, WEINTRAUB E, BRAMMER L, COX N, ANDERSON L J, et al. Mortality associated with influenza and respiratory syncytial virus in the United States. JAMA 2003; 289: 179-86.

7.- GARBINO J, GERBASE M W, WUNDERLI W, DEFFERNEZ CH, THOMAS Y, ROCHT T, et al. Lower respiratory illnesses. Improved diagnosis by molecular methods and clinical impact. Am J Respir Crit Care Med 2004;170: 1197-203.

8.- FALSEY A R, HENNESSEY P A, FORMICA M A, COX C, WALSH E E. Respiratory syncytial virus infection in elderly and high-risk adults. N Engl J Med 2005; 352: 1749-59.

9.- LEE N. High morbidity and mortality in adults hospitalized for respiratory syncytial virus infections. Clin Infect Dis 2013; 57: 1069-77.

10.- MARCOS M A, CAMPOS M, PIMAROLA T, MARTÍNEZ JA, MARTÍNEZ E, MENSA J, et al. The role of viruses in the aetiology of community-acquired pneumonia in adults. Antiviral Therapy 2006; 11: 3519.

11.- VAN DE POL A C, VAN LOON A M, WOLFS T F, JANSEN N J, NIJHUIS M, BRETELR E, et al. Increased detection of Respiratory Syncytial Virus, influenza viruses, parainfluenza viruses and adenoviruses with Real-Time PCR in samples from patients with respiratory symptoms. J Clin Microbiol 2007; 45: 2260-2.

12.- WELTE T. Risk factors and severity scores in hospitalized patients with community-acquired pneumonia: prediction of severity and mortality. Eur J Clin Microbiol Infect Dis 2011; 31: 33-47.

13.- VAN KRAIJ M G, VAN ELDEN L J, VAN LOON A M, HENDRIKSEN K A, LATERVEER L, DEKKER A W, et al. Frequent detection of respiratory viruses in adult recipients of stem cell transplants with the use of Real-Time polymerase chain reaction, compared with viral culture. Clin Infect Dis 2005; 40: 662-8.

14.- GIL R, UNDURRAGA A, SALDÍAS F, JIMÉNEZ $\mathrm{P}$, BARROS M, et al. Estudio multicéntrico de factores pronósticos en adultos hospitalizados por neumonía adquirida en la comunidad. Rev Med Chile 2006; 134 : 1357-66.

15.- DÍAZ A, BARRÍA P O, NIEDERMAN M, RESTREPO MI, DREYSE J, FUENTES G, et al. Etiology of Community-acquired Pneumonia in Hospitalized Patients in Chile. Chest 2007; 131:779-87.

16.- JENNINGS L C, ANDERSON T P, BEYNON K A, CHUA A, LAING R T R, WEMO A R, et al. Incidence and characteristics of viral community-acquired pneumonia in adults. Thorax 2008; 63:42-8.

17.- LUCHSINGER V, RUIZ M, ZUNINO E, MARTÍNEZ M A, MACHADO C, PIEDRA PA, et al. Communityacquired Pneumonia in Chile: the clinical relevance in the detection of viruses and atypical bacteria. Thorax 2013; 68: 1000-6.

18.- FALSEY A R, MCELHANEY J E, BERAN J, VAN ESSEN G A, DUVAL X, ESEN M, et al. Respiratory syncytial virus and other respiratory viral infections in older adults with moderate to severe influenza-like illness. J Infect Dis 2014; 209: 1873-8.

19.- MCLELLAN J S, RAY W C, PEEPLES M E. Structure and function of RSV surface glycoproteins Curr Top Microbiol Immunol 2013; 372: 83-104.

20.- SPANN K M, TRAN K C, COLLINS P L. Effect of nonstructural proteins NS1 and NS2 of human respiratory syncytial virus on interferon regulatory factor 3, NF-kappaB, and pro-inflammatory cytokines J Virol 2005; 79: 5353-62.

21.- GALIANO M, LUCHSINGER V, VIDELA C, DE SOUZA L, SÁNCHEZ-PUCH S, RICARTE C, et al. Antigenic diversity within respiratory syncytial virus strains isolated in Argentina and Chile. J Med Virol 2005; 77: 311-6.

22.- LUCHSINGER V, ELGUETA A, AVENDAÑO L F. Respiratory Syncytial Virus genomic and antigenic variants isolated in two pediatric hospitals in one season, in Chile. J Clin Virol 2008; 42: 260-3.

23.- IMAI T, HIESIMA K, HASKELL C, BABA M, NAGIRA M, NISHIMURA M, et al. Identification and molecular characterization of fractalkine receptor CX3CR1, which mediates both leukocyte migration and adhesion. Cell 1997; 91: 521-30.

24.- KURT-JONES E A, POPOVA L, KWINN L, HAYNES L M, JONES L R, TRIPP R A, et al. Pattern recognition receptors TLR4 and CD14 mediate response to respiratory syncytial virus. Nat Immunol 2000; 1 : 398-401.

25.- TAYYARI F, MARCHANT D, MORAES T J, DUAN W, MASTRANGELO P, HEGELE R G. Identification of nucleolin as a cellular receptor for respiratory syncytial virus. Nat Med 2011; 17: 1132-5.

26.- STEVENSON M D, MANSBACH J M MOWAD E, DUNN M, CLARK S, PIEDRA P A SULLIVAN A F, et al Prenatal versus postnatal tobacco smoke and intensive care use in children hospitalized with bronchiolitis Academic Pediatrics 2016; 16: 446-52.

27.- JONES L L, HASHIM A, MCKEEVER T, COOK D G, BRITTON J, LEONARDI-BEE J. Parental and household smoking and the increased risk of bronchitis, bronchiolitis and other lower respiratory infections in infancy; systematic review and meta-analysis. Respire Res 2011; $12: 5$.

28.- ZEPEDA G, DÍAZ PV, PINTO R, GAGGERO A,UASAPUD P. Seguimiento de lactantes hospitalizados por bronquiolitis por virus respiratorio sincicial: Evolución clínica, respuesta de atopia inflamatoria y marcadores. Resultados preliminares Rev Chil Enf Respir 2016; 32 : 18-24.

29.- MANSBACH J M, PIEDRA P A, STEVENSON M D, 
SULLIVAN A F, FORGEY T F, CLARK S. Prospective multicenter study of children with bronchiolitis requiring mechanical ventilation Pediatris 2012; 130: 492-500.

30.- JOZWIK A, HABIBI M S, PARAS A, ZHU J, GUVENEL A, et al. RSV-specific airway resident memory $\mathrm{CD} 8+\mathrm{T}$ cells and differential disease severity after experimental human infection Nature Commun. 2015. 21;6:10224. doi: 10.1038/ncomms1022.

31- JOHNSTON J, MAJUMDAR S R, FOX J D, MARRIE $\mathrm{T}$ J. Viral infection in adults hospitalized with community-acquired pneumonia: prevalence, pathogens, and presentation. Chest 2008; 134 : 1141-8.

32.- VOLLING C. Respiratory syncytial virus infectionassociated hospitalization in adults: a retrospective cohort study. BMC Infect Dis 2014; 14: 665.

33.- VAN ASTEN L, VAN DEN WIJNGAARD C, VAN PELT W VAN DE, KASSTEELE J, MEIJER A, et al. Mortality attributable to 9 common infections: significant effect of influenza A, respiratory syncytial virus, influenza B, norovirus, and parainfluenza in elderly persons J Infect Dis 2012; 206: 628-39.

34.- MALLOY A M, FALSEY A R, RUCKWARDT T J. Consequences of inmature and senescent e immune responses for infection with respiratory syncytial virus. Curr Top Microbiol Immunol 2013; 372: 211-31.

35.- HASEGAWA $\mathrm{K}$ J, JARTTI T, MANSBACH J M, LAHAM F R, JEWELL A M, ESPINOLA J A, et al Respiratory syncytial virus genomic load and disease severity. J Infect Dis 2015; 211: 1550-9.

36.- SCAGNOLARI C, MIDULLA F, SELVAGGI C, MONTELEONE K, BONCI E, PAPOFF P, et al. Evaluation of viral load in infants hospitalized with bronchiolitis caused by respiratory syncytial virus. Med Microb Immunol 2012; 201: 311-7.

37.- BRINT M E, HUGHES J M, SHAH A, MILLER C R, HARRISON L G, MEALS E A, et al. Prolonged viral replication and longitudinal viral dynamic differences among respiratory syncytial virus infected infants. Ped Res 2017; 82: 872-80.

38.- DÍAZ P V, VALDIVIA G, GAGGERO A A, BONO M R, ZEPEDA G, RIVAS M, et al. Pro-inflammatory cytokines in nasopharyngheal aspirate from hospitalized children with respiratory syncytial virus infection with or without Rhinovirus Bronchiolitis and use of the cytokines as predictors of illness severity Medicine 2015; 94 (39); e15122.

49.- TABARANI C M, BONVILLE C A, SURDEYAVARA M, BRANIGAN P, WANG D, HUANG D, et al. Novel inflammatory markers clinical risk factors and virus type associated with severe respiratory syncytial virus infection. Ped Infect Dis J 2013; 32: e437.

40.- WELLIVER T P GAROFALO R P, HOSAKOTE Y, HINTZ K H, AVENDAÑO L, SÁNCHEZ K, et al. Severe human lower respiratory tract illness caused by respiratory syncytial virus and influenza virus is characterized by the absence of pulmonary cytotoxic lymphocytes responses. J Infect Dis 2007; 195: 1126-36.

41.- LARRAÑAGA C L, AMPUERO S L, LUCHSINGER V F, CARRION F A, AGUILAR N V, MORALES P R, et al Impaired immune response in severe human lower tract respiratory infection by respiratory syncytial virus Ped Infect Dis J 2009; 28:867-73.

42.- ABU-HARB M, BELL F, FINN A, RAO WH, NIXON L, SHALE D, et al. IL-8 and neutrophil elastase levels in the respiratory tract of infants with RSV bronchiolitis Eur Respir J 1999; 14: 139-43.

43.- GILL MA, PALUCKA AK, BARTON T, GHAFFAR F, JAFRI H, BANCHEREAU J, et al. Mobilization of plasmacytoid and myeloid dendritic cells to mucosal sites in children with respiratory syncytial virus and other viral respiratory infections J Infect Dis 2005; 191: 105-15.

44.- JOHNSON T R, MERTZ S E, GITIBAN N, HAMMOND S, LEGALLO R, DURBIN R A, et al. Role for innate IFNs in determining respiratory syncytial virus immunopathology J Immunol 2005; 174: 7234-41.

45.- PEDRAZA-SÁNCHEZ S, HISE A G, RAMACHANDRA L, ARECHAVALETA-VELASCO F, KING C I. Reduced frequency of a CD14+CD16+ monocyte subset with high toll-like receptor 4 expression in cord blood compared to adult blood contributes to lipolysaccharides hyporesponsiveness in newborns. Clin Vaccine Immunol 2013; 20: 96-71.

46.- DÍAZ P V, PINTO R A, MAMANI R, UASAPUD P A, BONO M R, GAGGERO A A, et al. Increased expression of the glucocorticoid receptor $\beta$ in infants with RS bronchiolitis. Pediatrics 2012; 130: 804-11.

47.- OHUMA E O, OKIRO E A, OCHOLA R, SANDE C J, CANE P A, MEDLEY G F, et al. The natural history of respiratory syncytial virus in a bird cohort: the influence of age and previous infection on reinfection and disease. Am J Epidemiol 2012; 176: 794-802.

48.- LUCHSINGER V, PIEDRA P A, RUIZ M, ZUNINO E, MARTÍNEZ MA, MACHADO C, et al. Role of neutralizing antibodies in adults with community-acquired pneumonia by respiratory syncytial virus. Clin Infect Dis 2012; 54: 906-12.

49.- OCHOLA R, SANDE C, FEGAN G, SCOTT P D, MEDLEY G F, CANE PA, et al. The level and duration of RSV specific maternal IgG in infants in Kilifi Kenya. Plos One 4; e 8088 doi: 10,1371.

50.- PONNAPPAN S, PONNAPPAN U. Aging and immune function: molecular mechanisms to interventions. Antioxid Redox Signal 2011; 14: 1551-85.

51.- BUSSE P J, MATHUR S K. Age- related changes in immune function: effect on airway inflammation. J Alergy Clin Immunol 2010; 126: 690-9.

52.- RUSSELL C D, UNGER S A, WALTON M, SCHWARZE J. The Human Immune response to respiratory syncytial virus infection. Clin Microbiol Rev 2017; 30: 481-502. 
53.- RUCKWARDT T J, MORABITO K M, GRAHAM B S. Determinants of early immune responses to RSV infection. Curr Opin Virol 2016; 16: 151-6.

54.- MAHONY J, CHONG S, MERANTE F, YAGHOUBIAN S, SINHA T, LISLE C, et al. Development of a respiratory virus panel test for detection of twenty respiratory viruses by use of multiplex PCR and a fluid microbead based assay. J Clin Microbiol 2007; 45: 2965-70.

55.- JEONG J, KIM K, JEONG S, PARK J, LEE S, SEO Y. Comparison of sputum and nasopharyngeal swabs for detection of respiratory viruses. J Med Virol 2014; 86: 2122-7.

56.- PANEL RESPIRATORIO FILM ARRAY. http://www. biomerieuxchile.cl/diagnostico-clinico/productos/ biomerieux-worldwide.

57.- SIMOES E A, DEVINCENZO J P, BOECKH M, BONT L, CROWE J E JR, GRIFFITHS P, et al Challenges and opportunities in developing respiratory syncytial virus therapeutics. J Infect Dis 2015; 211 Suppl 1:S1-S20. doi: 10.1093/infdis/jiu828.

58.- GIRARDI B, ASTUDILLO P, ZÚÑIGA F. El programa IRA en Chile: hitos e historia. Rev Chil Pediatr 2001; 72: 292-300.

59.- MOCHIZUKI H, KUSUDA S, OKADA K, YOSHIHARA S, FURUYA H, SIMÕES E A. Palivizumab Prophylaxis in Preterm Infants and Subsequent Recurrent Wheezing: 6 Year Follow Up Study A J Respir Crit Care Med 2017; 196: 29-38.

60.- AMERICAN ACADEMY OF PEDIATRICS. Clini- cal Practice Guidelines: The Diagnosis, Management and Prevention of Bronchiolitis. Pediatrics 2014; 134 : e1474-e502.

61.- ANDERSON L J, DORMITZER PR, NOKES D J, RAPPUOLI R, ROCA A, GRAHAM B S. Strategic priorities for respiratory syncytial virus (RSV) vaccine development. Vaccine 2013; 31 Suppl 2: B209-15.

62.- KIM H W, CANCHOLA J G, BRANDT C G, PYLES G, CHANNOCK R M, JENSEN K, et al. Respiratory syncytial virus disease in infants despite prior administration of antigenic inactivated vaccine. Am J Epidemiol 1969; 89: 422-34.

63.- PATH ORGANIZATION. http://www.path.org/vaccineresources/details.php?i=1562 http://www.path.org/ publications/files/CVIA_rsv_snapshot_final.pdf

64.- REY-JURADO E, KALERGIS A M. Immunological features of Respiratory Syncytial Virus-caused Pneumonia. Implications for vaccine design. Int J Mol Sci 2017, 18,556; doi10.3390/ ijms18030556.

65.- REY-JURADO E, SOTO J, GÁLVEZ N, KALERGIS A M. A safe and efficient BCG vectored vaccine to prevent the disease caused by the human Respiratory Syncytial Virus. Human Vaccines \& Immunotherapeutics 2017, doi $10.1080 / 21645515$.

66.- GLENN G M, FRIES L F, THOMAS D N, SMITH G, KPAMEGAN H, LU H, FLYER D, et al A Randomized, Blinded, Controlled, Dose-Ranging Study of a Respiratory Syncytial Virus Recombinant Fusion (F) Nanoparticle Vaccine in Healthy Women of Child bearing Age. J Infect Dis 2016; 213: 411-42.

Correspondencia a:

Dra. Patricia Díaz A.

Programa de Fisiopatología, ICBM.

Facultad de Medicina, Universidad de Chile.

Avda. Salvador 486. Providencia, Santiago, Chile

Email: patriciadiazamor@gmail.com 